\title{
AZIZ NACIB AB'SABER: A NATUREZA, A SOCIEDADE E A PAISAGEM
}

\author{
*Adilson Avansi de Abreu
}

Aziz Nacib Ab'Saber (24/IO/I924 - I6/O3/2012) foi o cérebro, a propulsão e a âncora do conhecimento e interpretação da paisagem e da geografia brasileiras desenvolvidas na segunda metade do século XX e primeira década do século XXI.

Essa forte ligação com a paisagem foi reconhecida em diversas oportunidades pelo próprio Ab'Saber, que via nesse paradigma, inspirado em Pierre Monbeig, o método para ler e interpretar as relações do homem com a natureza na gênese do complexo geográfico, que integra o lugar, a região e o espaço.

Reproduzindo, sob certos aspectos, a trajetória de grandes nomes da Geografia - como Madame Jacqueline Beaujeu Garnier na França, por exemplo -, o professor Aziz parte da geomorfologia e da paisagem para chegar e interpretar os espaços geográficos.

O resultado dessa trajetória exprime-se com força nas obras produzidas principalmente a partir do último quartel do século XX, quando transcende vigorosamente o campo disciplinar da Geografia e dá contribuição fundamental também às Ciências Ambientais, à História, à Arqueologia e ao Planejamento Territorial. Toda sua obra é dotada, todavia, de forte geograficidade, mesmo quando assume feições inter e transdisciplinares ou aborda campos vizinhos da Geografia. É exatamente essa geograficidade que permite identificar nele o mais importante geógrafo brasileiro das últimas décadas.

Relatar sua obra é tarefa impossível para esta nota. Todavia, pode-se ter uma visão global dela a partir de duas publicações recentes dedicadas a ele: a primeira é $O$ que é ser geógrafo: memórias profissionais de Aziz Nacib Ab'Saber, em depoimento à Cynara Menezes (Rio de Janeiro, Editora Record, 2007); a segunda é A obra de Aziz Nacib Ab'Saber, organizada por May Christine Modenesi-Gautieri et alii, (São Paulo, Beca-BALL Edições Ltda., 20IO).

Essas duas referências são contrastantes e complementares. A primeira é relativamente compacta, com I68 páginas, de viés autobiográfico-memorialístico e estilo quase coloquial. Leitura agradabilíssima. Nela são arroladas as principais obras do autor, de forma bastante seletiva, mas, mesmo assim, totalizando 58 referências entre os anos de I949 e 2007.

A segunda corresponde a uma obra de fôlego que ilumina toda a produção científica e a atuação do professor Aziz, em um texto que chega a 582 páginas. É aberta por uma súmula biográfica, que aborda desde sua origem familiar (que integra troncos libaneses e paulistas), passando pela formação acadêmica, o desenvolvimento das atividades profissionais, as influências sofridas em sua trajetória, com destaque para os temas mais significativos de sua produção científica, sua atuação no planejamento territorial e nas questões nacionais, encerrando com os cargos ocupados. Seguem-se 30 capítulos escritos por autores convidados, que escolheram artigos do professor Aziz para releitura e reflexão crítica. Em cada capítulo, além do texto do autor, o trabalho comentado também é reproduzido. Os três primeiros capítulos fogem parcialmente a essa estrutura, embora mantenham o espírito do programa da obra. O livro é acompanhado de um DVD com praticamente toda a obra do Prof. Aziz em formato PDF.

\footnotetext{
* Professor titular de Geografia da Faculdade de Filosofia, Letras e Ciências Humanas da Universidade de São Paulo (FFLCH-USP) e Pró-Reitor de Cultura e Extensão Universitária da USP no período de 1997 a 2005 - Av. Professor Lineu Prestes, 338 - Cidade Universitária - São Paulo - SP - 05508-900 - e-mail: avansiabreu@gmail.com.
} 


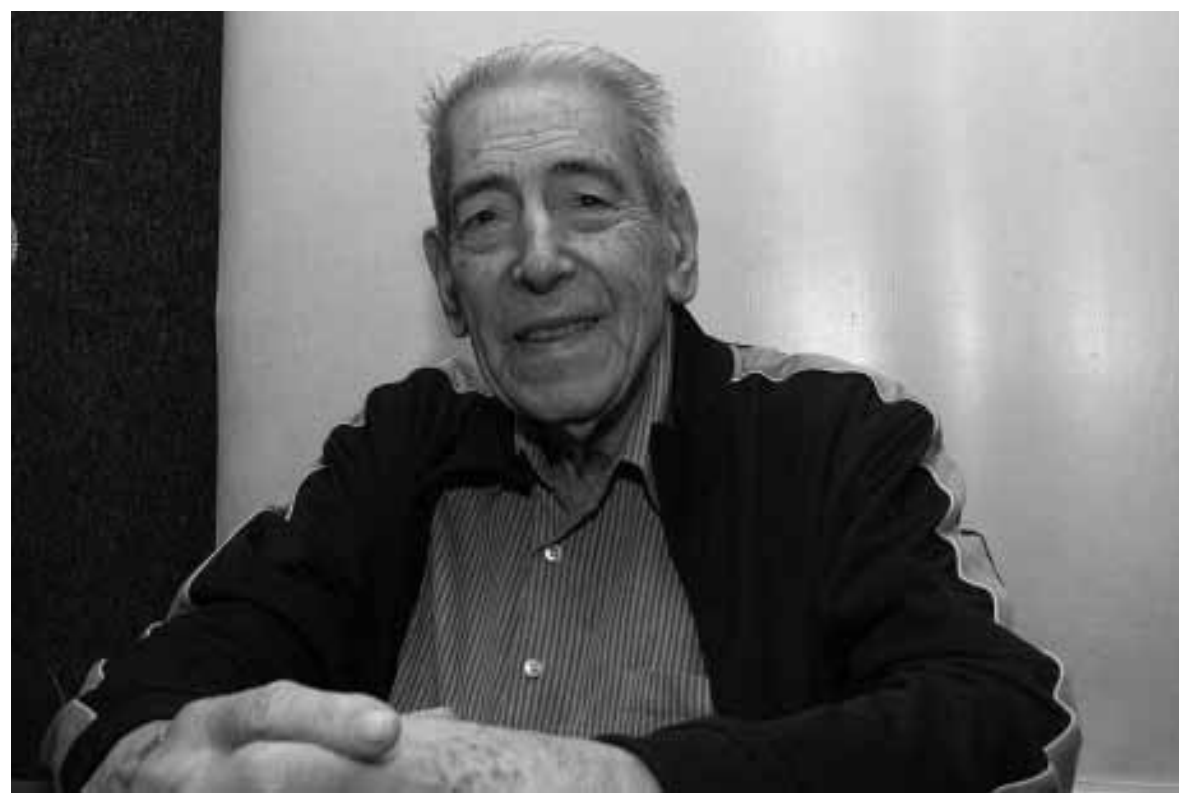

Professor Aziz no lançamento do livro A obra de Aziz Nacib Ab'Sáber, da Editora Beca-BALL

Edição Ltda., no auditório da Geografia e História. Foto: Francisco Emolo/ Jornal da USP.

Essas duas obras permitem ver o papel de liderança e de inovações que o professor Aziz exerceu na ciência brasileira. Gostaria, todavia, de formular de maneira resumida o aspecto mais relevante e certamente de longa duração de sua obra.

Ele repousa em uma ruptura com o passado clássico da interpretação da paisagem, herdado da escola anglo-saxônica - fortemente apoiado no paradigma davisiano da Geomorfologia, incorporado pela escola francesa de Geografia, que o trouxe para a Faculdade de Filosofia, Ciências e Letras da USP em I934 - e a formulação de um paradigma próprio, que começa a se materializar a partir do Congresso Internacional de Geografia, patrocinado pela União Geográfica Internacional, no Rio de Janeiro, em I956.

Nesse congresso, o professor Aziz vai se confrontar com a interpretação do relevo e da paisagem elaborada a partir da escola alemã de Geografia e de Geomorfologia, que valorizava muito mais os processos em todas as dimensões: do relevo à sociedade. Como contraponto a William Morris Davis surgem: Walther Penck, com a análise dialética do relevo (dinâmica interna x dinâmica externa), produzindo formas e depósitos correlativos; Siegfried Passarge, com a integração da natureza física e biológica produzindo os cinturões paisagísticos da terra, com sua geomorfologia fisiológica, que irá originar a expressão fisiologia da paisagem, tão bem conceituada pelo professor Aziz, e Edwin Fells, que examina a ação econômica do homem na face da terra e identifica seu papel morfogenético.

No confronto desses paradigmas, Ab’Saber desenvolverá sua própria visão metodológica, a partir de rico trabalho de campo apoiado em densa pesquisa documental.

Em 1956, defende sua tese de doutorado intitulada Geomorfologia do sítio urbano de São Paulo, na qual consolida uma visão já mais processual que o modelo davisiano de Geomorfologia. Em I965, em sua tese de livre-docência, Da participação das depressões periféricas e superfícies aplainadas na compartimentação do Planalto Brasileiro, ele já trabalha com método próprio, que será formalizado com rigor e clareza no terceiro item da introdução de sua tese de cátedra, defendida em 1968, intitulada Bases geomorfológicas para o estudo do Quaternário em São Paulo. O texto deste capítulo foi publicado na série Geomorfologia do Instituto de Geografia da USP - n. 18 e é, até hoje, a mais importante contribuição conceitual e metodológica no campo da Geomorfologia produzida no Brasil. Serviu de base teórica e operacional para um grande número de trabalhos teóricos e aplicados, não só no campo da Geomorfologia, mas também em inúmeros trabalhos voltados, de maneira mais abrangente, para a paisagem, do ponto de vista teórico e prático. 
A releitura deste texto guia, até hoje, os que se ocupam com a paisagem em seus diferentes momentos processuais: desde as relativamente pouco alteradas pelo homem até as profundamente transformadas por sua ação economizante e social que, em países com estrutura econômica injusta como o Brasil, implica em fragilidades e riscos ambientais e sociais.

Aí repousa a geograficidade de sua obra em todos os temas que aborda, particularmente os relacionados aos desequilíbrios ambientais em suas diferentes formas de ocorrências nas cidades e nos campos.

Cumpre registrar ainda a enorme sensibilidade que o professor Aziz tinha em relação aos problemas sociais, que frequentemente motivou duras críticas aos governantes. Ele atuou não só no plano intelectual e acadêmico, mas também na ação que procurava apoiar, materialmente, populações desvalidas. É digno de nota seu empenho pela melhoria da educação, particularmente dos jovens, com seu esforço para criar bibliotecas em todos ambientes pelo qual passou.

Nasceu no dia 24 de outubro de I924 em São Luiz do Paraitinga e faleceu no dia I6 de março de 2012 em São Paulo. Era professor emérito da Faculdade de Filosofia, Letras e Giências Humanas da USP. Foi presidente da Sociedade Brasileira para o Progresso da Ciência (SBPG). Recebeu inúmeros prêmios nacionais e internacionais, dentre os quais merecem destaque a Palma Acadêmica do governo francês, o Prêmio Internacional de Ecologia e o Prêmio UNESCO para Ciência e Meio Ambiente, a Grã-Cruz em Ciências da Terra pela Ordem Nacional do Mérito Gientífico. Era Professor Honorário do Instituto de Estudos Avançados da USP, Membro Honorário da Sociedade de Arqueologia Brasileira e Presidente de Honra da SBPG. 